\title{
METHODOLOGY FOR A TASK-SPECIFIC AND PERSONALISED DEVELOPMENT OF AN INITIAL EXOSKELETON DESIGN
}

\author{
Drees, Tobias; \\ Kunnen, Steffen; \\ Pluhnau, Robin; \\ Nagarajah, Arun \\ University of Duisburg-Essen
}

\begin{abstract}
The use of exoskeletons promises improved ergonomics, empowerment of users and prevention of musculoskeletal disorders. However, the development process is complex and a generic development methodology that will guide and assist designers through it is missing. The goal of this paper is to describe a methodological approach that will assist the conceptual design of exoskeletons. Based on derived methodological requirements, activities 1, 2, and 3 of the VDI 2221 (Methodology for the development of technical products) are specified to adapt the generic guideline to the development process of exoskeletons. These activities include the analysis and determination of the relationship between the use case, product requirements and motions, technical functions, and design solutions. For generating a list of product requirements designers must focus on the workers' motions and needs for a for a task-specific and personalised development. Use case specific movements are generalised by using rotational and translational basic movements that result in six degrees of freedom and from which a function structure is derived. The method is critically reviewed based on the established methodological requirements.
\end{abstract}

Keywords: Design methodology, Early design phases, Conceptual design, Exoskeleton, Research methodologies and methods

\section{Contact:}

Drees, Tobias

University of Duisburg-Essen

Institute of product engineering

Germany

tobias.drees@uni-due.de 


\section{INTRODUCTION}

\subsection{Motivation}

Decision-makers in companies must deal with the challenge of managing various changes in workforce structures and their impact on working conditions. Despite ongoing advances in automation and technology, the need for flexible, physically demanding human work will persist in the future. Measures must be developed to enable employees to carry out their professions in the long term and without physical harm. (Calzavara et al., 2020)

In this context, the development and use of industrial exoskeletons address three main changes in the workforce structure. Firstly, the occurrence of work-related musculoskeletal disorders (WMSDs) are one of the main causes of health-related withdrawal from employment and absenteeism (European Agency for Safety and Health at Work, 2010). A variety of risk factors contribute to the probability of WMSDs occurring, e.g. the manual handling of loads, repetitive movements, working in unergonomic postures and exposure to vibrations (da Costa and Vieira, 2010). In 2016, more than $23.5 \%$ of the workforce in Germany was engaged in work that exposes them to one or more of the mentioned risk factors (Federal Institute for Occupational Safety and Health, 2017). Even within the profession of physical therapists, who study body mechanics and injury prevention early in their education, more than $90 \%$ suffer from WMSDs during their lifetime (Vieira et al., 2016). Secondly, a survey shows that more than $50 \%$ of the companies see the shortage of skilled workers, especially in physically demanding working activities, as the greatest threat to the development of their business (Association of German Chambers of Industry and Commerce, 2019). Thirdly, the workforce is getting older, which results in a higher overall risk for WMSDs. The demographic ageing of society has a big influence on the mean average age of workers, which becomes visible by the employment rate of 60-64-year-olds. In 2017, $53 \%$ of women and $64 \%$ of men that age were employed, compared to $25 \%$ and $41 \%$ in 2007 (Federal Statistical Office, 2018). This is because of a lack of young skilled workers due to demographic ageing, government restrictions on early retirement options and the company's dependence on elderly workers.

\subsection{Problem statement}

To counteract and adapt to the changing workforce structure, the use of exoskeletons promises a reduction of physical stress on employees as well as the possibility of enabling physically handicapped or elderly persons to work. Furthermore, exoskeletons offer a reduction of the occurrence of workplace health risks, such as WMSDs. Companies will not only benefit from the flexibility of the human worker but also from the enabled power and endurance from the robotic device. (Dahmen et al., 2018)

The development of exoskeletons for use in work environments has been a research focus for only a few years (Gull et al., 2020), with the primary focus on working principles, technical details and biomechanical adaptation to the human body. However, the development process of exoskeletons remains complex as it currently has no specific guidelines on how to get the development systematically structured (Bostelman et al., 2017). Consequently, a key issue in developing exoskeletons that still must be addressed is a missing generic development methodology, which will guide and support engineers through the big variety of different use cases, tasks, and solutions (Hansen et al., 2018).

Referring to Sauer et al. (2003), a systematically structured design task is an important part in the early design phase, where the features of the product are established. Conventional process models like the VDI 2221 guideline or the Munich Procedural Model allow a holistic approach and overview of the development process (VDI, 2019; Ponn and Lindemann, 2011). Accompanying methods that supplement the general methodological development are to be found in the relevant literature (Roth, 2000; Feldhusen and Grote, 2013; Lindemann, 2009). Design methodologies enable a controlled and verifiable approach that is appropriate to the design task to obtain resilient solutions (Feldhusen and Grote, 2013). However, especially in a dynamic, evolving, and quick changing industry, a rigid, inflexible, and not specified methodology might hinder the development rather than assist the designer (Birkhofer et al., 2002; Sauer et al., 2003). As a result, industries are reluctant to adopt (theoretical) design methodologies, which also applies to the exoskeleton industry. Badke-Schaub et al. (2011) identify specific deficits to design methods that need to be addressed. As one of the deficits they indicate that design methodologies are not adapted to different situational conditions and thus they do not consider the industry or the specific design process they are used for. Referring to that, Feldhusen and Grote (2013) point out that for a methodology to be usable in practice, it must contain precise 
instructions for action, which a conventional process model cannot provide on its own. Consequently, the methodology must be adapted to the individual application situation (Ponn and Lindemann, 2011). Thus, to reduce uncertainties and avoid inappropriate strategies in the design of exoskeletons, a methodological approach adapted to the specific design process of exoskeletons is needed. Such a methodology will oppose the complexity of the development process, which includes many uncertainties, different design parameters, solution options, and involved scientific disciplines, to reach the goal of designing task-specific and personalised exoskeletons.

\section{STATE OF THE ART}

\subsection{Definition of exoskeletons}

A literature review shows that there is no standard definition of technical exoskeletons yet, although many sentence fragments of existing definitions use the same wording or address at least the same working principles. This indicates that there is a common understanding of what exoskeletons are. Having a closer look at a variety of definitions published in scientific papers, reference books, and project reports it is possible to identify the common phrases in these definitions.

Exoskeletons are wearable, external mechanical structures (Looze et al., 2016; Karvouniaria et al., 2017) that are sometimes referred to as wearable robots (Pons, 2008; Bai and Rasmussen, 2011) or wearable devices (Toxiri et al., 2018a; Ngai, 2010). A common understanding is the fact that a technical exoskeleton is worn by the user or attached to him. Some authors continue this idea and limit the term exoskeleton to anthropomorphic devices (Herr, 2009; Perry et al., 2007; Chen et al., 2020). If defined in this way, it emphasises the characteristic that exoskeletons follow the movements of the wearers' limbs and joints in a parallel way. In some cases, the definition includes the main purpose of an exoskeleton to emphasise its field of application:

- $\quad$ power enhancement and providing assistive force (Huysamen et al., 2018; Toxiri et al., 2018a),

- lowering/reducing physical stress (Hensel and Keil, 2018; Ippolito et al., 2020),

- augmenting and restoring the performance or power of the wearer (Herr, 2009; Exoskeleton Report, 2015; Karvouniaria et al., 2017),

- $\quad$ enhancing strength, speed and endurcance (Low et al., 2005).

Furthermore, exoskeletons may be defined according to their specific use case or body segment they assist, e.g. assisting the lower limb (Chiș et al., 2020) or walking in general (Kuhn and Freyberg-Hanl, 2018). However, in this way other fields of applications are neglected.

Table 1. Phrases of definitions of exoskeletons

\begin{tabular}{ccc} 
Statement & Number of entries & Applicable \\
\hline Body worn / wearable / attached to the body & 25 & $\mathrm{X}$ \\
\hline Increase performance & 14 & $\mathrm{X}$ \\
\hline Mechanical structure & 11 & \\
\hline (Power/Force/Performance) Support & 11 & $\mathrm{X}$ \\
\hline Reduce of loads/stress & 9 & $\mathrm{X}$ \\
\hline Application of force on body & 7 & \\
\hline Human-machine interface & 6 & $\mathrm{X}$ \\
\hline Support recovery & 5 & 4 \\
\hline Anthropomorphic figure & 4 & \\
\hline Exchange of energy & 4 &
\end{tabular}

Table 1 presents an overview of the phrases and the number of times those are found in the literature review. It also indicates whether those phrases are applicable for a holistic definition so that their various fields of application and their variety of main functions are included.

Considering these thoughts altogether, exoskeletons can be defined as follows:

Exoskeletons are wearable devices that interact mechanically with the wearers' body (Schick, 2018). This device is modelled based on the human anatomy in a way that its joints are adapted to those of the human body to allow and support normal body movements (Fleischer and Zimmermann, 2008). There is an effective transfer of energy between the wearer and the device (Pons, 2008). 


\subsection{Analysing existing methods in developing exoskeletons}

Research papers and projects focus mainly on the technical details of parts and assemblies as well as analysing the biomechanical movements of the user and the corresponding exoskeleton (Toxiri et al., 2018b; Yong et al., 2019). Recently, studies regarding the effectiveness and the potential of exoskeletons are published as well (de Vries and de Looze, 2019; Bosch et al., 2016; Fox et al., 2019; Theurel and Desbrosses, 2019; Koopman et al., 2020).

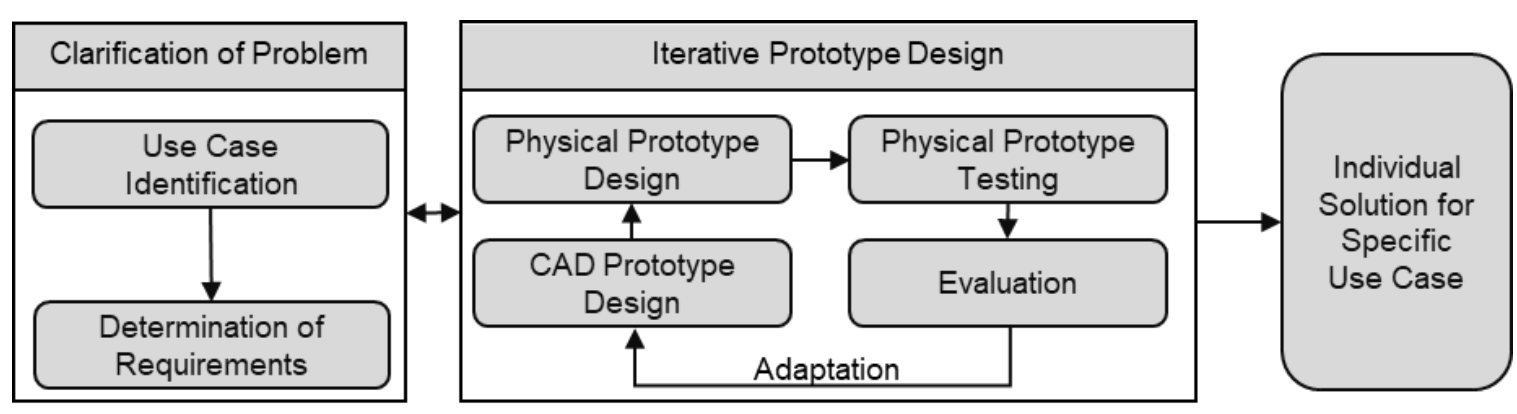

Figure 1. Recent default developing process of exoskeletons

A default developing process can be identified by analysing previous research activities and developments of exoskeletons. This default developing process is shown in Figure 1. Within the process, two phases can be identified. The clarification of the problem is achieved by identification of the specific use case and determination of subsequent requirements. The development of the exoskeleton regarding establishing a working and sufficient individual solution uses an iterative approach. The iterative procedure consists of the development of a prototype in CAD and physical, labour-intensive prototype testing, evaluation of the results and subsequent adaptation of the prototype under revised requirements. These iterative steps also include the potential for virtual prototyping to study trajectories and loads on the exoskeleton. (Hansen et al., 2018)

Constantinescu et al. (2018) describe a method for the digital examination of prototypes at the workplace and especially for the coupling of the CAD exoskeleton with a digital humanoid in a digital workplace. This method is placed within the iterative prototype design phase. The method describes a continuous improvement process of coupling the digital (CAD-) exoskeleton to a digital worker (Constantinescu et al., 2016), simulating the working process, analysing the coupling mistakes, and optimising them in a further coupling phase. This method allows the improvement of the implementation of exoskeletons in a specific workplace. Thus, the number of physical prototype iterations to test the real-life combination is decreased. However, it is not mentioned how the initial exoskeleton CAD-design is developed.

Cruz Martínez and Z.-Avilés (2020) present a methodology for the design of upper limb rehabilitation devices. It is divided into three phases. In the first phase (initial phase) a conceptual model is developed and the device requirements are addressed. Within their second phase (engineering phase) the authors suggest a differentiation of the main exoskeleton development into several subsets that are designed individually. These are on the one hand the aided body part or joints and on the other hand the electronic systems and the human-machine-interface. It gives a holistic overview of the development process but does not include specific steps on how the conceptual design parameters result from the determined motions, functions, and requirements. The engineering phase can be applied to the iterative prototype design phase by providing further specifying steps to design the initial prototype. The third phase (evaluation) is specific for the development of rehabilitation devices.

Heidari et al. (2018) propose a task-based design methodology for the development of exoskeletons. This method is based on a detailed assessment of the human body movements as well as an identification of body movement paths instead of considering the human (robotic) joint movements. It addresses the implementation of task- and movement-based kinematics into the development of exoskeletons and thus provides the possibility of a task-specific and personalised solution. However, for each new application there is no methodology described that will improve determining future development solutions. 


\section{RESEARCH GOALS AND METHODOLOGICAL REQUIREMENTS}

As stated before, a systematic approach will improve the overall development process (Hansen et al., 2018). Existing methodologies for exoskeletons focus either on the iterative prototype design phase (Dahmen and Constantinescu, 2020; Constantinescu et al., 2018) or on the specifics of a single task within the development process while neglecting the overall design process (Heidari et al., 2018; Hansen et al., 2018). However, a methodology for the development of an initial conceptual exoskeleton design specific to a particular application remains unknown. Thus, the goal of this paper is to describe an approach of a holistic methodology that will help the initial design of task-specific and personalised exoskeletons by focusing on the conception phase of the product development process. The selection of a suitable basic methodology, which should be adapted to the specific exoskeleton design process, must consider that industrial exoskeletons often rely on mechanical elements such as springs and dampers ("passive") instead of mechatronic actuators ("active") due to the lower weight and thus improved ergonomics. Consequently, as a generic methodology VDI 2221 and its accompanying guideline VDI 2222 is chosen (VDI, 1997). VDI 2221 functions as a core guideline for product development that can be applied to all types of technical products and systems and its design processes. It is especially useful and applicable for mechanical products. Alternatives like VDI 2206 and the Munich Procedural Model are not suitable because a more linear approach is preferred to counteract the difficulty of many disciplines involved in the novel design process of (passive) exoskeletons as well as to ensure easy transferability of the approach to the characteristics of exoskeletons (VDI, 2004; Ponn and Lindemann, 2011). Referring to the problem statement, the following questions arise:

- How can VDI 2221 be adapted to clarify the development process of exoskeletons?

- Which specifying steps and tools must be implemented in VDI 2221 (Activities 1 - 3) to develop more mature initial exoskeleton designs? (VDI, 2019)

VDI 2221 and VDI 2222 clarify the necessary steps that designers must follow when developing an exoskeleton, but both guidelines only rudimentary give instructions on how to execute these steps. This must be addressed. It is also desirable that the number of prototype design iterations is reduced through an improved initial design. The specificity of the various working activities must also be considered. Following these considerations, Table 2 shows the derived methodological requirements.

Table 2. Methodological requirements

\begin{tabular}{|l|l|}
\hline 1 & $\begin{array}{l}\text { The transition between analysing the use case, analysing body movements in working conditions, } \\
\text { derived requirements, functions, and the initial design draft must be improved and structured }\end{array}$ \\
\hline 2 & Steps and tools that are adapted to the concept development of exoskeletons must be clarified \\
\hline 3 & The degree of maturity in early development phases must be increased \\
\hline 4 & The transferability between different use cases must be ensured. \\
\hline
\end{tabular}

\section{METHODOLOGICAL APPROACH OF DEVELOPING EXOSKELETONS}

Figure 2 describes a systematic approach with specific steps in developing initial exoskeleton solutions based on the general structure of activities 1 - 3 of VDI 2221. Specifying the first phase of VDI 2221, which clarifies the problem or task, the proposed subtasks focus on analysing the users' needs and movements during their task fulfilment and the identification of task-specific requirements. The analysis of the workers' movements can be done in separate ways. Motion capture refers to the process of recording the movements of people. It is used to describe movement trajectories that are essential for the determination of specific design parameters, e.g. joint movements (Chen et al., 2017) and requirements regarding the biomechanical structure of the exoskeleton (Folgheraiter et al., 2009; Allotta et al., 2015). The motions also must be described linguistically. A detailed linguistic description preferably results from capturing the motions with assisting devices. If this is not possible due to e.g. the ambient conditions at the workplace, a stand-alone description must be provided. The user-focused analysis emphasises the need to adapt the exoskeleton to the needs of the workers and proactively addresses user perception and usability of the device. The result of activity one is a list of requirements.

The first step of the second activity is the identification of basic motions that are performed within the specific task. As a general distinction, the motion of each human body part or joint can be represented by identifying its rotational and translational movements in three dimensions $\mathrm{x}, \mathrm{y}$, and $\mathrm{z}$. The degrees 
of freedom of the human skeletal system limit the human body's movements and the solution space for potential exoskeleton designs. This allows to generate a database set of basic motions, from which the relevant ones are picked and assist the determination of essential task-specific functions.

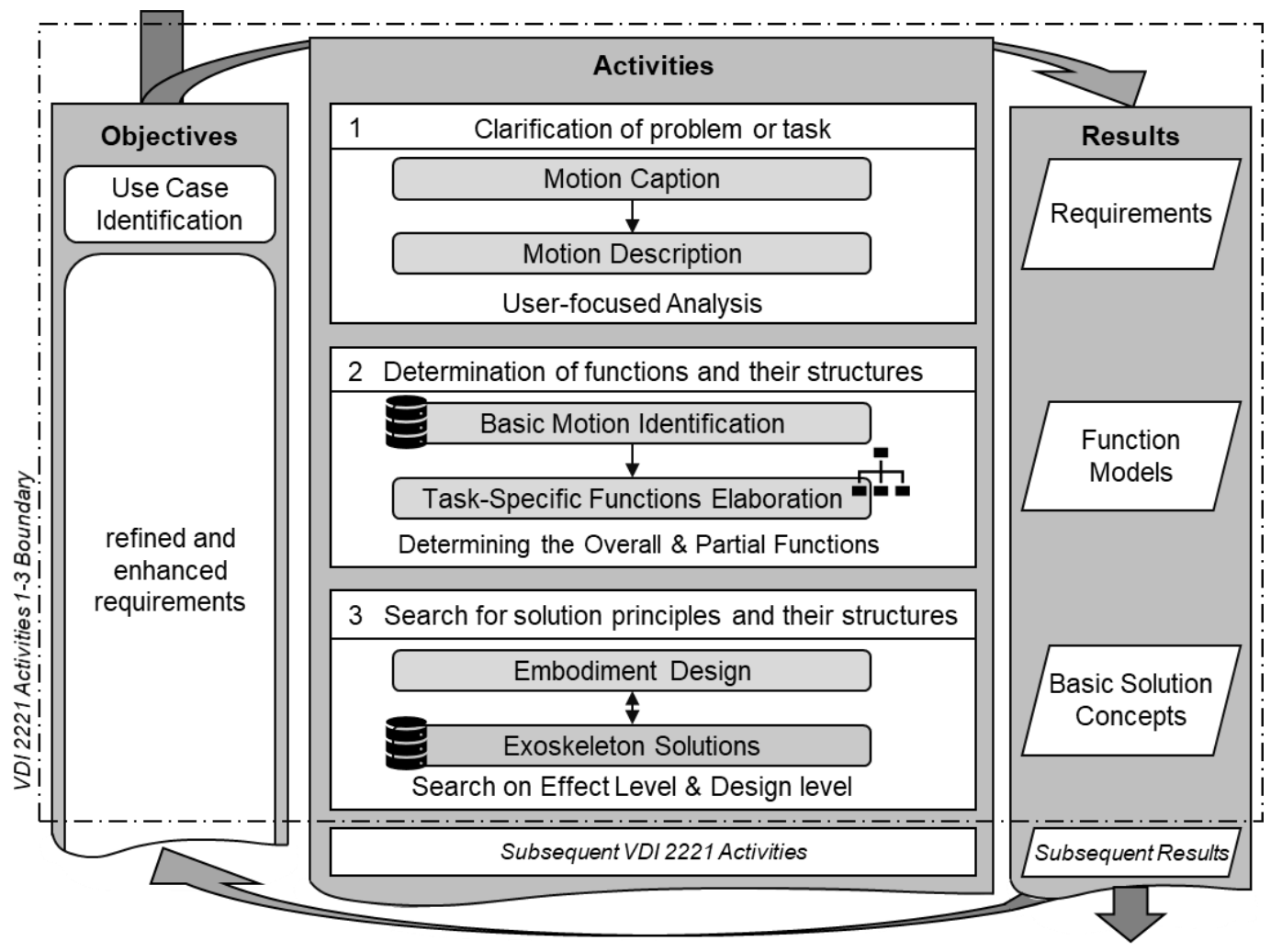

Figure 2. Approach in developing initial design solutions of exoskeletons adapted from VDI 2221 (VDI, 2019)

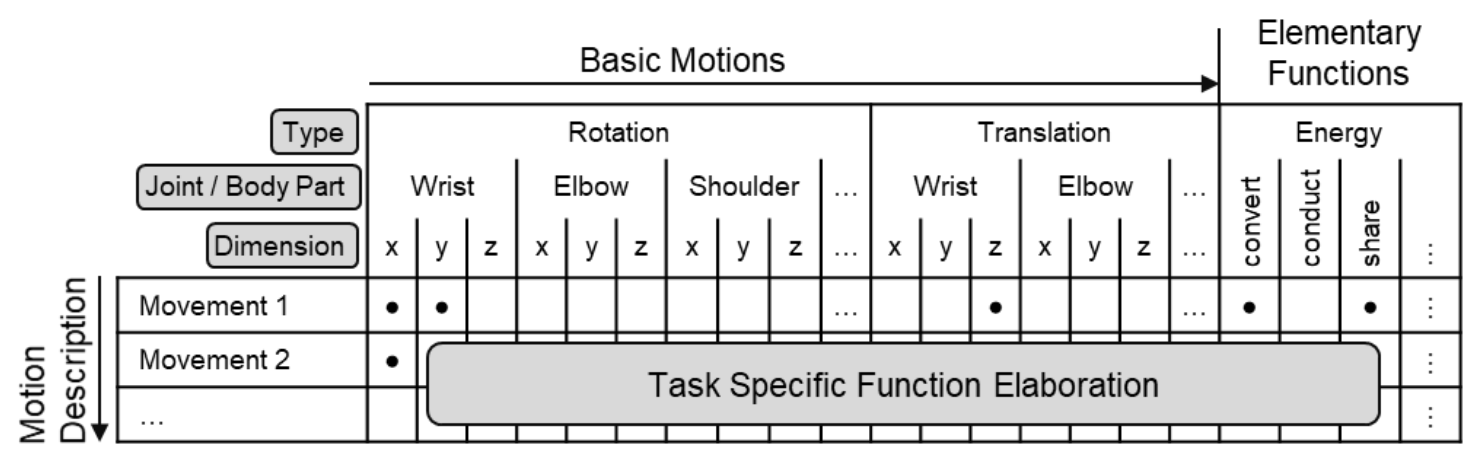

Figure 3. ExoMotion matrix

The elaboration of the functions will be done by matching the single movements and the corresponding basic motions. Figure 3 describes this connection in the ExoMotion matrix. Besides the movement of human joints and limbs the flow of energy within the movements need to be addressed as well, as it was partially done by (Cruz Martínez and Z.-Avilés, 2020). Koller and Kastrup (1998) provide a suitable and in other fields applied list of elementary energy operators when dealing with flows of energy and function structures. These can be used within the ExoMotion matrix. Based on VDI 2222 these steps can be applied to overall and partial functions. Task-specific function models are the result of activity two. In the third activity of VDI 2221, solution principles and their structures are sought by combining the functional structure and requirements into an initial exoskeleton prototype design (basic solution). As guidance for the designer, previous exoskeleton solutions are saved in a database and made available from it. The database should contain solutions in different forms of representation. It is important to not only have holistic exoskeleton solutions at hand, but also use detailed designs or even just design principles and physical effects as these are found in construction catalogues. This activity allows the combination of identified solutions, which might be reduced to their effective structures, with the functions that realise them. Moreover, new solution concepts are developed through new combinations 
of known function-embodiment mapping. The result are basic exoskeleton solutions, which represent the initial design drafts that are more mature than previous design concepts.

\section{DIscussion}

In the approach presented, the first three VDI 2221 activities are specified for the development process of exoskeletons. A structured development method will guide engineers as well as other parties through the holistic development process, providing them a useful step-by-step approach.

Two key factors in generating a list of requirements were identified. On the one hand designers must focus on the workers' motions for a task-specific design and on the other hand they must focus on the workers' needs for personalising the exoskeleton. The former can be achieved by motion capture devices that are widely used in different industries. In recent exoskeleton developments optical motion capture using camera systems and markers on the workers' body is an utilised method (Huysamen et al., 2020; Hansen et al., 2018). A helpful tool for the latter is the design of personas to better understands the users' needs (Nielsen, 2013). Figure 4 shows a persona for a waste collector, whose profession is physically demanding. However, personas represent only one possible way of analysing the workers' need. Further subjective and objective methods, such as structured interviews, questionnaires, statistical key figures, or measurement and evaluation of the physical work environment must be discussed and examined for their effectiveness in generating a specific list of requirements. DIN EN 16710-2 proposes further methods that are applicable in this context (DIN Deutsches Institut für Normung e. V., 2016). Consequently, a whole set of tools will be available for the designer.
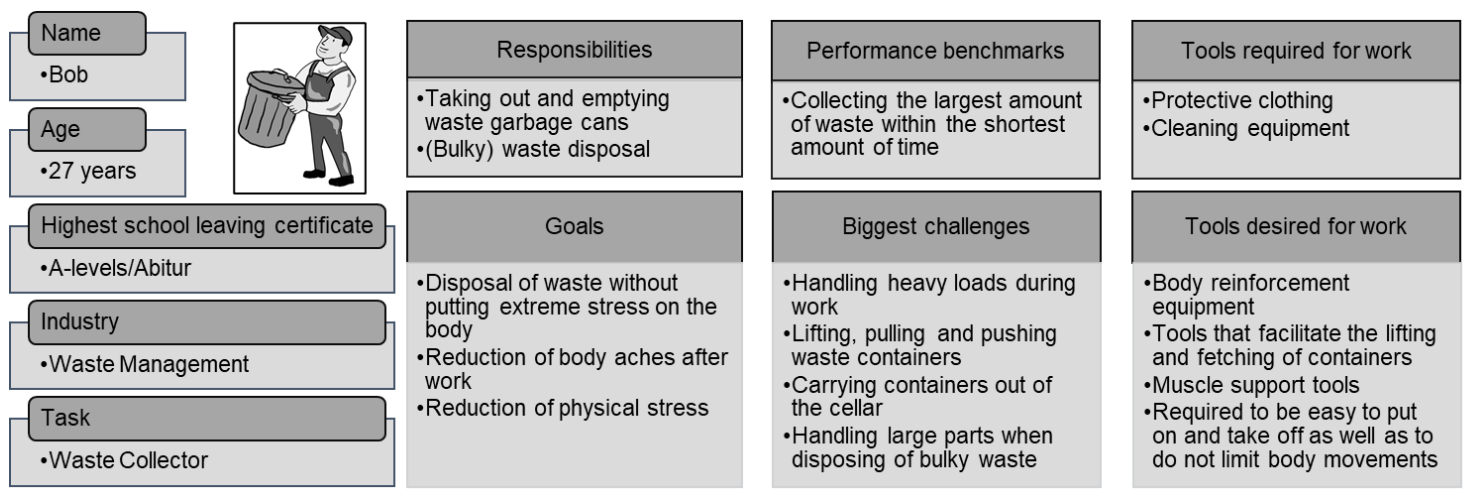

Figure 4. Persona of a waste collector

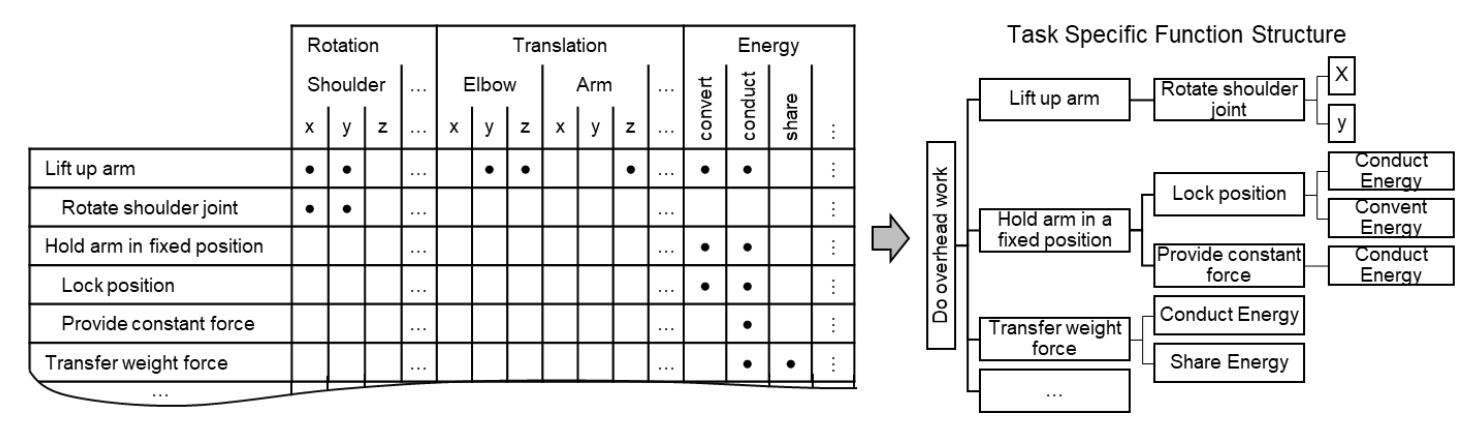

Figure 5. ExoMotion matrix and derived function structure for doing overhead work

For the description of basic motions, the most elementary way is chosen by using three-dimensional rotational and translational movements. These are supplemented by elementary energy functions. As shown in the ExoMotion matrix in Figure 5, by applying this concept to the general task of doing overhead work it allows to build up the connection between movements and functions. The motion description in the first column can be supplemented with identified movements from activity one and, thus, provides a guideline to elaborate a task-specific function structure. The proposed usage of basic motion- and embodiment-databases will improve the foundation for future exoskeleton developments. As the solutions are stored in different forms of representation it will allow a holistic and a fractal view on previous design solutions. This step is the most difficult within the holistic development process as it transfers design ideas from a descriptive function-focused point of view into a (virtual) prototype design concept. 
Referring to the methodological requirements established in Table 2, by specifying the activities in the presented way developers have a guideline at hand that improves the transition between analysing the use case and creating the initial design. It becomes apparent, which steps are necessary and crucial for developing a task-specific and personalised initial exoskeleton design. Nevertheless, this conference paper presents an outline of a holistic development approach and, thus, the foundation for future research activities in this field. Steps and corresponding tools/methods are proposed and applied but must still be validated regarding its effectiveness. The right set of tools as a combination of various methods to derivate requirements, motions, function, embodiment, and their correlations must be identified. It can be said that after their identification and analysis the presented approach will have clarified the specific development process of exoskeletons.

If applied, the methodology has the potential of increasing the degree of maturity in early development phases. It gives precise instructions for actions that are adapted to the individual use case and their effectiveness builds upon specific databases. However, the concept must still be validated and applied to an exoskeleton development to measure and compare the degree of maturity to the default design process of exoskeletons.

By concentrating on basis motions and elementary functions the transferability of the methodology to various use cases is given. To sum up, it can be said that the requirements introduced in Table 2 are met. Nevertheless, there is still various research to conduct to finalise the evaluation of the presented method, as will be pointed out below.

\section{CONCLUSION AND OUTLOOK}

Exoskeletons have the potential to play a key role in enabling (elderly) industrial workers to execute physically demanding jobs. The necessity of a systematic development process of exoskeletons was demonstrated and an approach was presented to improve the initial product design. The proposed methodology provides a useful step-by-step instruction based on the guideline VDI 2221. It shows the relationship between analysing the use case, deriving requirements, task-specific functions, and design solutions. Nevertheless, the concept presented is theoretical in nature and needs further research in several areas. Within the plan of action for employing and validating the methodology, specific userfocused methods that are useful in the evaluation of workers' needs must be identified. A further research focus is the application of the basic movement and the development of its database by analysing which joints and body parts need to be addressed. Previous exoskeleton developments must be analysed to determine their commonalities and differences, and their principal solutions. This data will be implemented into databases that provide useful insights for new developments. Furthermore, a way to match necessary functions and principal solutions effectively needs to be evaluated. Once all mentioned information is collected and the databases are set up, an exoskeleton for the test case of a waste collector will be designed as a proof of concept. For this, the physical realisation at a company is planned.

To conclude, the general potential of the deployment of (industrial) exoskeletons is undoubtedly great though it needs to be released effectively and target-oriented with the right measures, tools, and methods.

\section{REFERENCES}

Allotta, B., Conti, R., Governi, L., Meli, E., Ridolfi, A. and Volpe, Y. (2015), “Development and experimental testing of a portable hand exoskeleton", pp. 5339-5344.

Association of German Chambers of Industry and Commerce (2019), DIHK-Konjunkturumfrage Herbst 2019.

Badke-Schaub, P., Daalhuizen, J. and Roozenburg, N. (2011), "Towards a Designer-Centred Methodology: Descriptive Considerations and Prescriptive Reflections", in Birkhofer, H. (Ed.), The Future of Design Methodology, Springer London, London, pp. 181-197. http://doi.org/10.1007/978-0-85729-615-3.

Bai, S. and Rasmussen, J. (2011), "Modelling of physical Human-Root interaction for Exoskeleton designs". Thematic Conference Multibody Dynamics 2011.

Birkhofer, H., Kloberdanz, H., Sauer, T. and Berger, B. (2002), "Why mehods don't work and how to get them to work", DS 29: Proceedings of EDIProD 2002, pp. 29-36.

Bosch, T., van Eck, J., Knitel, K. and Looze, M. de (2016), "The effects of a passive exoskeleton on muscle activity, discomfort and endurance time in forward bending work", Applied ergonomics, Vol. 54, pp. 212-217. http://doi.org/10.1016/j.apergo.2015.12.003.

Bostelman, R., Messina, E. and Foufou, S. (2017), "Cross-industry standard test method developments: from manufacturing to wearable robots", Frontiers of Information Technology \& Electronic Engineering, Vol. 18 No. 10, pp. 1447-1457. http://doi.org/10.1631/FITEE.1601316. 
Calzavara, M., Battini, D., Bogataj, D., Sgarbossa, F. and Zennaro, I. (2020), “Ageing workforce management in manufacturing systems: state of the art and future research agenda", International Journal of Production Research, Vol. 58 No. 3, pp. 729-747. http://doi.org/10.1080/00207543.2019.1600759.

Chen, B., Zhong, C.-H., Zhao, X., Ma, H., Guan, X., Li, X., Liang, F.-Y., Cheng, J.C.Y., Qin, L., Law, S.-W. and Liao, W.-H. (2017), "A wearable exoskeleton suit for motion assistance to paralysed patients", Journal of orthopaedic translation, Vol. 11, pp. 7-18. http://doi.org/10.1016/j.jot.2017.02.007.

Chen, B., Zi, B., Qin, L. and Pan, Q. (2020), "State-of-the-art research in robotic hip exoskeletons: A general review", Journal of orthopaedic translation, Vol. 20, pp. 4-13. http://doi.org/10.1016/j.jot.2019.09.006.

Chiș, L.C., Copotoiu, M. and Moldovan, L. (2020), "Different Types of Exoskeletons can Improve the Life of Spinal Cord Injury’s Patients - a Meta-Analysis”, Procedia Manufacturing, Vol. 46, pp. 844-849. http://doi.org/10.1016/j.promfg.2020.04.014.

Constantinescu, C., Muresan, P.-C. and Simon, G.-M. (2016), "JackEx: The New Digital Manufacturing Resource for Optimization of Exoskeleton-based Factory Environments", Procedia CIRP, Vol. 50, pp. 508-511. http://doi.org/10.1016/j.procir.2016.05.048.

Constantinescu, C., Popescu, D., Todorovic, O., Virlan, O. and Tinca, V. (2018), "Methodology of Realising The Digital Twins of Exoskeleton-Centered Workplaces", Applied Mathematics, Mechanics, and Engineering, Vol. 61 No. III, pp. 441-448.

Cruz Martínez, G.M. and Z.-Avilés, L.A. (2020), "Design Methodology for Rehabilitation Robots: Application in an Exoskeleton for Upper Limb Rehabilitation”, Applied Sciences, Vol. 10 No. 16, p. 5459. http://doi.org/10.3390/app10165459.

da Costa, B.R. and Vieira, E.R. (2010), "Risk factors for work-related musculoskeletal disorders: A systematic review of recent longitudinal studies", American journal of industrial medicine, Vol. 53 No. 3, pp. $285-323$. http://doi.org/10.1002/ajim.20750.

Dahmen, C. and Constantinescu, C. (2020), "Methodology of Employing Exoskeleton Technology in Manufacturing by Considering Time-Related and Ergonomics Influences”, Applied Sciences, Vol. 10 No. 5, p. 1591. http://doi.org/10.3390/app10051591.

Dahmen, C., Wöllecke, F. and Constantinescu, C. (2018), "Challenges and Possible Solutions for Enhancing the Workplaces of the Future by Integrating Smart and Adaptive Exoskeletons”, Procedia CIRP, Vol. 67, pp. 268-273. http://doi.org/10.1016/j.procir.2017.12.211.

de Vries, A. and de Looze, M. (2019), "The Effect of Arm Support Exoskeletons in Realistic Work Activities: A Review Study”, Journal of Ergonomics, Vol. 9 No. 255. http://doi.org/10.35248/2165-7556.19.9.255.

DIN Deutsches Institut für Normung e. V. (2016), Verfahren der Ergonomie: Teil 2: Eine Methode für die Arbeitsanalyse zur Unterstützung von Entwicklung und Design No. 16710-2, Beuth Verlag GmbH, Berlin.

European Agency for Safety and Health at Work (2010), OSH in figures: work-related musculoskeletal disorders in the EU - Facts and figures, European risk observatory report, Luxembourg.

Exoskeleton Report (2015), “What is an exoskeleton?”, available at: https://exoskeletonreport.com/what-is-anexoskeleton/ (accessed 4 November 2020).

Federal Institute for Occupational Safety and Health (BAuA) (2017), Sicherheit und Gesundheit bei der Arbeit Berichtsjahr 2016

Federal Statistical Office (2018), "Arbeitsmarkt auf einen Blick - Deutschland und Europa”.

Feldhusen, J. and Grote, K.-H. (2013), Pahl/Beitz Konstruktionslehre, Springer-Verlag, Berlin, Heidelberg. http://doi.org/10.1007/978-3-642-29569-0.

Fleischer, C. and Zimmermann, A. (2008), "Auswertung von elektromyographischen Signalen zur Steuerung von Exoskeletten”, Informatik - Forschung und Entwicklung, Vol. 22 No. 3, pp. 173-183. http://doi.org/10.1007/s00450-008-0042-8.

Folgheraiter, M., Gea, J. de, Bongardt, B., Albiez, J. and Kirchner, F. (2009), "Bio-inspired control of an arm exoskeleton joint with active-compliant actuation system", Applied Bionics and Biomechanics, Vol. 6 No. 2, pp. 193-204. http://doi.org/10.1080/11762320902840187.

Fox, S., Aranko, O., Heilala, J. and Vahala, P. (2019), "Exoskeletons - Comprehensive, comparative and critical analyses of their potential to improve manufacturing performance", Journal of Manufacturing Technology Management. http://doi.org/10.1108/JMTM-01-2019-0023.

Gull, M.A., Bai, S. and Bak, T. (2020), “A Review on Design of Upper Limb Exoskeletons”, Robotics, Vol. 9 No. 1, p. 16. http://doi.org/10.3390/robotics9010016.

Hansen, C., Gosselin, F., Ben Mansour, K., Devos, P. and Marin, F. (2018), "Design-validation of a hand exoskeleton using musculoskeletal modeling”, Applied ergonomics, Vol. 68, pp. 283-288. http://doi.org/10.1016/j.apergo.2017.11.015.

Heidari, O., Wolbrecht, E.T., Perez-Gracia, A. and Yihun, Y.S. (2018), “A task-based design methodology for robotic exoskeletons", Journal of rehabilitation and assistive technologies engineering, Vol. 5. http://doi.org/10.1177/2055668318800672.

Hensel, R. and Keil, M. (2018), "Subjektive Evaluation industrieller Exoskelette im Rahmen von Feldstudien an ausgewählten Arbeitsplätzen”, Zeitschrift für Arbeitswissenschaft, Vol. 72 No. 4, pp. 252-263. http://doi.org/10.1007/s41449-018-0122-y. 
Herr, H. (2009), "Exoskeletons and orthoses: classification, design challenges and future directions", Journal of neuroengineering and rehabilitation, Vol. 6, p. 21. http://doi.org/10.1186/1743-0003-6-21.

Huysamen, K., Looze, M. de, Bosch, T., Ortiz, J., Toxiri, S. and O’Sullivan, L.W. (2018), “Assessment of an active industrial exoskeleton to aid dynamic lifting and lowering manual handling tasks", Applied ergonomics, Vol. 68, pp. 125-131. http://doi.org/10.1016/j.apergo.2017.11.004.

Huysamen, K., Power, V. and O'Sullivan, L. (2020), "Kinematic and kinetic functional requirements for industrial exoskeletons for lifting tasks and overhead lifting”, Ergonomics, Vol. 63 No. 7, pp. 818-830. http://doi.org/10.1080/00140139.2020.1759698.

Ippolito, D., Constantinescu, C. and Rusu, C.A. (2020), "Enhancement of human-centered workplace design and optimization with Exoskeleton technology”, Procedia CIRP, Vol. 91, pp. 243-248. http://doi.org/10.1016/j.procir.2020.02.173.

Karvouniaria, A., Michalos, G., Dimitropoulos, N. and Makris, S. (2017), “An approach for exoskeleton integration in manufacturing lines using Virtual Reality techniques”, Procedia CIRP, Vol. 65, pp. 32-37. http://doi.org/10.1016/j.procir.2017.04.009.

Koller, R. and Kastrup, N. (1998), Prinziplösungen zur Konstruktion technischer Produkte, Springer-Verlag, Berlin, Heidelberg.

Koopman, A.S., Kingma, I., Looze, M.P. de and van Dieën, J.H. (2020), "Effects of a passive back exoskeleton on the mechanical loading of the low-back during symmetric lifting", Journal of biomechanics, Vol. 102. http://doi.org/10.1016/j.jbiomech.2019.109486.

Kuhn, D. and Freyberg-Hanl, B. (2018), "Exoskelett: Therapiesystem oder Hilfsmittel zum Behinderungsausgleich", Trauma und Berufskrankheit, Vol. 20 No. S4, pp. 254-259. http://doi.org/10.1007/s10039-018-0394-7.

Lindemann, U. (2009), Methodische Entwicklung technischer Produkte, Springer-Verlag, Berlin, Heidelberg. http://doi.org/10.1007/978-3-642-01423-9.

Looze, M.P. de, Bosch, T., Krause, F., Stadler, K.S. and O’Sullivan, L.W. (2016), "Exoskeletons for industrial application and their potential effects on physical work load", Ergonomics, Vol. 59 No. 5, pp. 671-681. http://doi.org/10.1080/00140139.2015.1081988.

Low, K.H., Liu, X. and Yu, H. (2005), "Development of NTU wearable exoskeleton system for assistive technologies", in IEEE International Conference Mechatronics and Automation, 2005, pp. 1099-1106.

Ngai, M. (2010), "Design of a Forearm Exoskeleton for Supination/Pronation Assistance in Daily Activities", Bachelor Thesis, Department of Electrical and Computer Engineering, McMaster University, Hamilton.

Nielsen, L. (2013), Personas - user focused design, Human-computer interaction series, Springer, London.

Perry, J.C., Rosen, J. and Burns, S. (2007), “Upper-Limb Powered Exoskeleton Design”, IEEE/ASME Transactions on Mechatronics, Vol. 12 No. 4, pp. 408-417. http://doi.org/10.1109/TMECH.2007.901934.

Ponn, J. and Lindemann, U. (2011), Konzeptentwicklung und Gestaltung technischer Produkte, Springer-Verlag, Berlin, Heidelberg. http://doi.org/10.1007/978-3-642-20580-4.

Pons, J.L. (Ed.) (2008), Wearable robots: Biomechatronic exoskeletons, Wiley, Hoboken N.J.

Roth, K. (2000), Konstruieren mit Konstruktionskatalogen: Band 1: Konstruktionslehre, 3. Auflage, erweitert und neu gestaltet, Springer-Verlag, Berlin. http://doi.org/10.1007/978-3-642-17466-7.

Sauer, T., Kloberdanz, H., Walter, S., Berger, B. and Birkhofer, H. (2003), "Describing Solutions to the Conceptual Phase - Structured and User-Oriented”, DS 31: Proceedings of ICED 03, the 14th International Conference on Engineering Design, pp. 49-58.

Schick, R. (2018), "Einsatz von Exoskeletten in der Arbeitswelt”, Zentralblatt für Arbeitsmedizin, Arbeitsschutz und Ergonomie, Vol. 68 No. 5, pp. 266-269. http://doi.org/10.1007/s40664-018-0299-0.

Theurel, J. and Desbrosses, K. (2019), "Occupational Exoskeletons: Overview of Their Benefits and Limitations in Preventing Work-Related Musculoskeletal Disorders”, IISE Transactions on Occupational Ergonomics and Human Factors, Vol. 7 No. 3-4, pp. 264-280. http://doi.org/10.1080/24725838.2019.1638331.

Toxiri, S., Calanca, A., Ortiz, J., Fiorini, P. and Caldwell, D.G. (2018a), "A Parallel-Elastic Actuator for a Torque-Controlled Back-Support Exoskeleton”, IEEE Robotics and Automation Letters, Vol. 3 No. 1, pp. 492-499. http://doi.org/10.1109/LRA.2017.2768120.

Toxiri, S., Koopman, A.S., Lazzaroni, M., Ortiz, J., Power, V., Looze, M.P. de, O’Sullivan, L. and Caldwell, D.G. (2018b), "Rationale, Implementation and Evaluation of Assistive Strategies for an Active BackSupport Exoskeleton”, Frontiers in Robotics and AI, Vol. 5. http://doi.org/10.3389/frobt.2018.00053.

VDI (1997), Methodic development of Solution principles No. 2222, Beuth-Verlag, Berlin.

VDI (2004), Design methodology for mechatronic systems No. 2206, Beuth-Verlag, Berlin.

VDI (2019), Design of technical products and systems No. 2221 Part 1, Beuth-Verlag, Berlin.

Vieira, E.R., Schneider, P., Guidera, C., Gadotti, I.C. and Brunt, D. (2016), "Work-related musculoskeletal disorders among physical therapists: A systematic review", Journal of back and musculoskeletal rehabilitation, Vol. 29 No. 3, pp. 417-428. http://doi.org/10.3233/BMR-150649.

Yong, X., Yan, Z., Wang, C., Wang, C., Li, N. and Wu, X. (2019), "Ergonomic Mechanical Design and Assessment of a Waist Assist Exoskeleton for Reducing Lumbar Loads During Lifting Task", Micromachines, Vol. 10 No. 7. http://doi.org/10.3390/mi10070463. 